\title{
Interference of germination time on chemical composition and antioxidant capacity of white sesame (Sesamum Indicum)
}

\author{
Luísa Fernandes de Menezes MARES ${ }^{1}$, Maria Cristina PASSOS ${ }^{1}$, Camila Carvalho MENEZES ${ }^{1 *}$
}

\begin{abstract}
The consumption of white sesame has become a healthy option for those who are concerned about health and wish to reduce oxidative stress. The germination has been used an effective method to increase the nutrients availability and thus provide a better nutritional quality of these seeds. Due to the lack of researches about sesame germination the objective of this study was to evaluate the different times of germination on the chemical composition (moisture, fat, protein and ashes), the antioxidant capacity and the phenolic compounds of white sesame. The germination occurred inside a greenhouse with controlled temperature at $30^{\circ} \mathrm{C}$ and the variables were analyzed in the times $0,24,36$ and 48 hours of germination. The process increased the levels of moisture and reduced the levels of fat, protein and ashes. On the other hand, it also increased the antioxidant capacity by two methods and raised the quantity of total phenolic compounds. Based in the present study and in others similar works, it is possible to affirm that the germination process increase the white sesames' antioxidant capacity, however further studies are needed to evaluate a better environmental condition of germination and others factors that may affect the composition.
\end{abstract}

Keywords: nutrients; phenolic compounds; antioxidant capacity; time.

Practical Application: The germination of white sesame for 24, 36 and 48 hours increases its antioxidant capacity.

\section{Introduction}

There is a growing concern about a healthier life style and healthy foods. Eating habits are changing quickly making agro industry adapt to new products, ensuring healthy and nutritious foods. In this context, the seeds germination process is an old and effective method, which is improving and expanding the nutritional quality of foods (López-Amorós et al., 2006). In the process are formed considerable endogenous hydrolysis enzymes, modifying the grain structure, which means, large molecules will reduce into small molecules as simple sugar, peptides and amino acids. These small molecules will be formed from starch, non-starch polysaccharides and proteins (large molecules). As result, also, occur an increase in nutrients content such as vitamins, minerals and antioxidant capacity due to the bioactive compounds formed in the germination process. (Hassani et al., 2016).

In this process there are factors which may affect the chemical composition and biochemical constituents of seeds, such as plant species, seed diversity and the germination situations (Hahm et al., 2009). The germination time is also a relevant fact and could interfere in germination process (López-Amorós et al., 2006). According to Hahm et al. (2009), distinct times of germination influences in the nutritional quality of sesame seeds (Sesamum Indicum).

The sesame is considered a healthy food and it has been used to improve the nutritional status and to avoid diseases in several countries, principally in Asia (Chen et al., 2005). Correspond to
Pedaliaceous family and, possibly, is the oldest grain consumed by humans. It's commonly used as oil for cooking and recognized as healthy food by the Japanese, therefore Japan is considered the leader in sesame seed imports (Hahm et al., 2009). The greater producer is India, around 800 thousand tons in the year of 2014 (Food and Agriculture Organization, 2014).

In addition, the sesame seeds have high values of protein, vitamin B1, fibers and it is a great source of minerals, such as phosphorus, iron, magnesium, calcium, copper and e zinc (Pathak et al., 2014), and also presents average of $50 \%$ of oil, predominantly unsaturated fat. The fatty acid existents in sesame oil are the oleic acid and linoleic acid, with the percentage between $41 \%$ - $45 \%$ and $37 \%$ - $42 \%$, respectively. It was recently discovered substances, in sesame seeds, that promote health and are considered antioxidants, such as sesamin, sesamolin, sesamol and sesaminol (Hahm et al., 2009). Also presents high fiber contents, phenolic compounds, phytates, lignans and tocopherols. Therefore, have been reported great benefits of sesame ingestion, such as higher testosterone levels and consequently an improvement in reproductive process, glycemia and body weight balance, and a decrease in serum cholesterol (Chen et al., 2005).

The consumption of antioxidants in a diet is essential to avoid the oxidative stress. Recently studies are associating flavanoids, an antioxidant compound, with a decrease in cancer risk and cardiovascular disease (Žilić et al., 2104). Although exist a huge 
interest in sesame consumption, there are not a plenty of studies about the nutritional characteristics of seeds germination and seeds in nature produced in Brazil, (Silva et al., 2014), where the consumption has been intensifying due to the Japanese food influence.

The sesame seed was introduced in Brazil in the 16th century and it is traditionally produced in northeast region by small producers for local consumption.

The regions with greater production are in the states of Goias and Mato Grosso, but it is also produced in the states of Minas Gerais and São Paulo (Arriel et al., 2007). Due to the sesame nutritional qualities, the facilities on cultivation and planting, and the adaptabilities to the climatic conditions, the sesame consumption has been expanding in the Brazilian market. The sesames are used in nature and in the food industry, such as in breads, cookies, candies, sesame paste (tahine) and also in salads and rice (Queiroga et al., 2008). Furthermore, the sesame oil may be used in food, pharmaceutical and chemical industry.

There are few researches assessing the relation between seeds germination in different environment conditions and time, with nutritional and functional quality. Therefore, it's justified the evaluation of the interference on germination time about the nutritional composition and antioxidant capacity of white sesame in this study.

\section{Material and methods}

The white sesame seeds were obtained in local commerce in the city of Ouro Preto - MG. The germination and the physical and chemical analyzes were performed in the laboratories of Food Technology and Bromatology of Federal University of Ouro Preto - UFOP, MG, Brazil, respectively.

\subsection{Germination process}

The germination process was realized according to Amistá \& Tavano (2013) with some adaptations. For each treatment (germination time) were weighed 20 grams of white sesame seeds, of which were submersed in $100 \mathrm{~mL}$ of potable water for 8 hours. Then, were placed in glasses jars (capacity of $200 \mathrm{~mL}$ ) with an opening covered with an organza tissue, which remained inverted, allowing the entry of air and exit of water. All recipients containing sesame were placed inside a chamber with controlled temperature at $30 \pm 1{ }^{\circ} \mathrm{C}$, with relative moisture to $98 \pm 2 \%$ and without luminosity. The sesame was germinated in these conditions for 24, 36 e 48 hours, and with nature sesame, characterized the four treatments of study, which were analyzed in triplicate. Instantly after the germination process, parts of the samples were dried at $65^{\circ} \mathrm{C}$ for 24 hours for the realization of antioxidant capacity and total phenolic compounds determination, as was performed by Hahm et al. (2009). All samples were triturated and then frozen at $-50 \pm 2{ }^{\circ} \mathrm{C}$ where were maintained until the analyses moment.

\subsection{Chemical composition}

The moisture, ashes and ether extract determinations were realized by a gravimetric method and the protein content by nitrogen determination with conversion factor equal to 6.3.
All data were determinate according with the Association of Official Analytical Chemists (Association of Official Analytical Chemists, 2012).

\subsection{Preparation of extracts for determination of total phenolic compounds and antioxidant capacity}

The extracts were obtained according the method reported by Larrauri et al. (1997) with adjustments. Were weight 10 grams of white sesame seeds dried in a greenhouse at $65^{\circ} \mathrm{C}$ for 24 hours e triturated, then was added $40 \mathrm{~mL}$ of methanol/water $(50 / 50, \mathrm{v} / \mathrm{v})$ for the beginning of the extract process. The samples were left at rest for 2 hours at ambient temperature and without luminosity, and, then, centrifuged at $3000 \mathrm{rpm}$ for 30 minutes. The supernatant was recovery and stored under cooling. Afterwards, was added $40 \mathrm{~mL}$ of acetone/water $(70 / 30, \mathrm{v} / \mathrm{v})$ in tubes containing residues, which one remaining at rest for 2 hours at ambient temperature and without luminosity followed by centrifugation at $3000 \mathrm{rpm}$ for 30 minutes. The supernatant was recovered. For the methanol and acetone extracts were combined and the final volume was completed to $100 \mathrm{~mL}$ with distilled water.

\subsection{Determination of total phenolic compounds}

The total phenolic compounds were determinate by Folin - Ciocalteu method with adaptations (Waterhouse, 2002). Was mixed $0.5 \mathrm{~mL}$ of diluted extract in specifics proportions for each sample with $2.5 \mathrm{~mL}$ of Folin-Ciocalteu (10\%) reagent and, then, was added $2 \mathrm{~mL}$ of sodium carbonate at $4 \%$. The mixtures were homogenized using vortex for 10 seconds and maintained at rest and without luminosity for 2 hours. Aqueous solutions of Gallic acid and ethanol P.A. were used for obtaining the standard curve and white, respectively. The reading was done in a spectrophotometer with a wavelength of $750 \mathrm{~nm}$.

\section{5 $\mathrm{Fe}^{3}+$ Reducing Antioxidant Power (FRAP)}

The capacity to reduce the ion sulphate (FRAP) was realized according by Pulido et al. (2000) techniques, with adaptations by Rufino et al. (2006). The FRAP reagent was obtained by mixing TPTZ (10 mM) solutions, Ferric Chloride $(20 \mathrm{mM})$ and acetate buffer $0.3 \mathrm{M}$ ( $\mathrm{pH} 3.6$ ) in 10:10:100 proportion, respectively. $90 \mu \mathrm{L}$ aliquots of the extracts were mixed with $2.7 \mathrm{~mL}$ of distilled water and $2.7 \mathrm{~mL}$ of FRAP reagent, and maintaining at $37^{\circ} \mathrm{C}$ for 30 minutes. The reading was done in a spectrophotometer with wavelength of $595 \mathrm{~nm}$. The standard curve was constructed using known concentrations of ferrous sulphate (500 a $2000 \mu \mathrm{M})$.

\subsection{Determination of antioxidant capacity by ABTS free radical scavenging activity}

The antioxidant capacity using the free radical 3-ethylbenzthiazoline-6-sulphonic acid (ABTS) was determinate by Miller et al. (1993) method, with adaptations by Rufino et al. (2007). The free radical ABTS was prepared using $7.5 \mathrm{~mL}$ of ABTS stock solution $(7 \mathrm{mM})$ and $132 \mu \mathrm{L}$ of potassium persulphate solution $(140 \mathrm{mM})$. The solution was maintained at rest for 16 hours at room temperature and without light exposure. For the determination, $30 \mu \mathrm{L}$ of extract dilution of each sample 
were added $3.0 \mathrm{~mL}$ of radical, which were homogenized in vortex for 10 seconds and left to stand in a room temperature for 6 minutes. It was realized in a spectrophotometer with a wavelength of $734 \mathrm{~nm}$. The standard curve was obtained from the Trolox solution $(2.000 \mu \mathrm{M})$.

\subsection{Statistical analysis}

The results were expressed as mean and standard deviation of three repetitions. The Kolmogorov-Smirnov test was applied to test the data normality. In case of normal distribution, the results were analyzed by ANOVA analysis. For the significant analysis $(\mathrm{p} \leq 0.05)$ were applied logistic regression $(\mathrm{p} \leq 0.05)$ to assess the interference in sesame germination time on the evaluated parameters. The Pearson correlation test $(p \leq 0.05)$ was realized to determine the correlation between the total phenolic compounds and the antioxidant capacity by different methods available. The statistical analyses were realized with the aid of software Statistical Package for Social Sciences (SPSS - 18.0 version).

\section{Results and discussion}

\subsection{Centesimal composition}

The increase in moisture was directly proportional $(\mathrm{p} \leq 0.05)$ to the germination time, that is, how greater was the time of sesame germination, greater the water absorption by the seed (Figure 1a). The same result was found by Megat et al. (2011) and Amistá \& Tavano (2013) where was found a significant increase of moisture after soy, peanut and rice, and quinoa germination, respectively. This increase in moisture is explained due to seed's hydration in germination process. How much more time germinating, more hydrated will be the grain (Martinez et al., 2011).

In relation to lipids content, the time of germination caused a significant interference $(p \leq 0.05)$ in values (Figure $1 b)$, that's means the lipids levels decreases with a higher germination time. Megat et al. (2011) found a significant lipids reduction during the germination process for soy, white, black, red and brown rice. This decrease could be explained due the use of lipid for the seeds growth, because according to Hahm et al. (2009) the fatty acids are used as energy for germination, and will be oxidized into carbon dioxide and water.

It was observed that the protein levels on the sample were inversely proportional to germination time $(\mathrm{p} \leq 0.05)$ (Figure $1 \mathrm{c})$. Megat et al. (2011) found a significant reduction on protein quantities after soy, peanut and rice germination. This could indicate that the protein synthesis is lower that the proteolysis in germination (Megat et al., 2011). This decrease could be due a higher protein dilution because of the great absorption of water during the germination. However, other authors as Martinez et al. (2011) and Ohtsubo et al. (2005) identified an increase of protein content during the germination process. Martinez et al. (2011) justified that this increase is due to an enzymatic synthesis or other components losses.

In relation to ashes, was possible to observe a reduction on ash content with increasing germination time (Figure 1d). Furthermore, Megat et al. (2011) and Ruiz \& Bressani (1990) found similar results on rice and amaranth seeds evaluation, respectively. This fact could be explained for the minerals loss during the germination process, because the food is washed before the germination begins (Megat et al., 2011). The ash

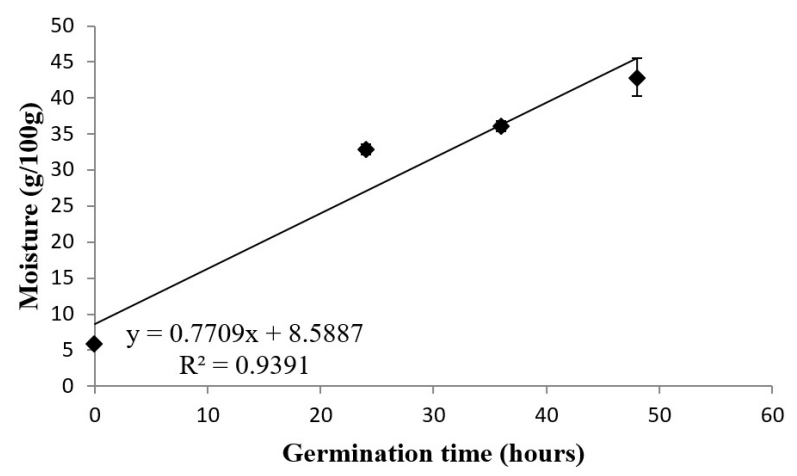

(a)

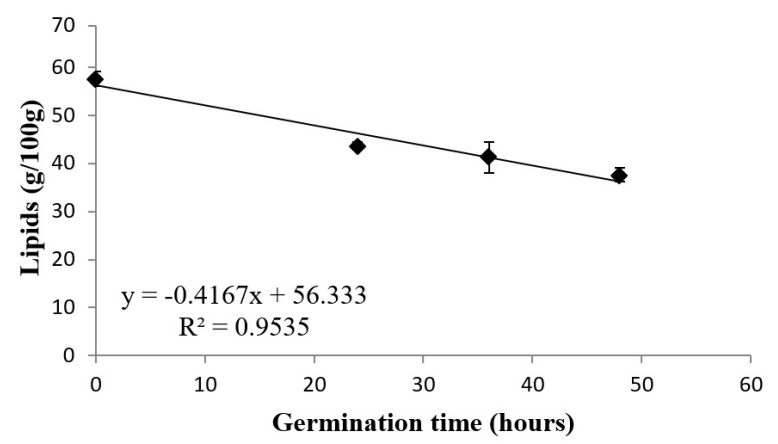

(b)

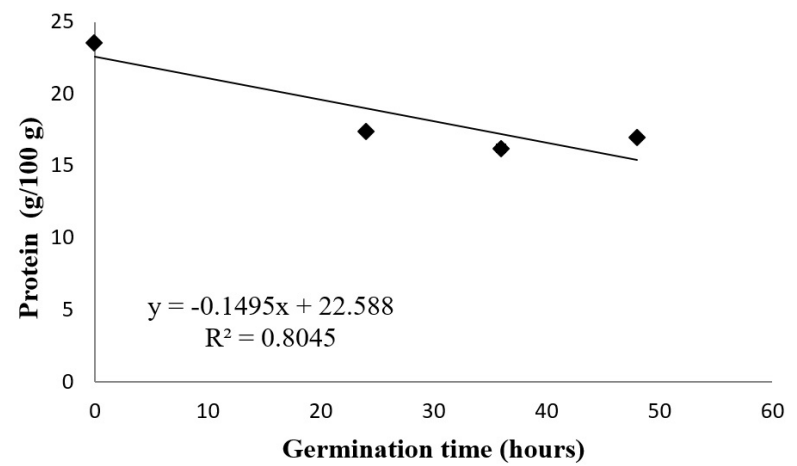

(c)

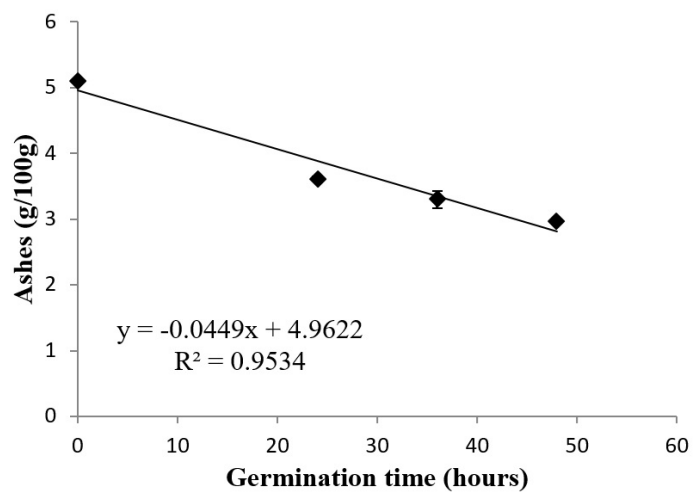

(d)

Figure 1. Interference of white sesame seeds in germination time about the content of moisture (a), lipids (b), proteins (c) and ashes (d). 
reduction could be also explained due to higher absorption of water by the germinated seed, diluting the total ashes content.

\subsection{Bioactive compound and antioxidant capacity}

The bioactive compounds are substances presents on foods and act as metabolic modulators capable of inhibiting the onset of degenerative diseases (Vizzoto et al., 2010). According Abderrahim et al. (2012), the germination increases the quantity of phenolic compounds and antioxidant capacity in grains. In germination method, due to biochemical process, are formed bioactive compounds with antioxidant function, such as phenolic compounds and tocopherols (Žilić et al., 2014).

The phenolic compounds in white sesame seed were analyzed during the germination time and it was observed an increase directly proportional to time (Figure 2). Xu et al. (2009) found an increase of phenolic compounds in oatmeal in different germination times (12, 24, 36 e 48 hours), as Troszynska et al. (2006) when was evaluated the mung beans (Vigma radiata L.). This fact could be justified because the germination releases the phenolic compounds that were connected and then increases the quantity of total phenolic (Kaukovirta-Norja et al., 2004). In contrast, Randhir et al. (2004) found a decrease in phenolic levels in mung beans seeds and according to Mbithi et al. (2001), this reduction is justified due to the pigmentation loss in legumes when germination occurs.

The Pearson correlation coefficient was analyzed to evaluate if the total phenolic contents interfered directly in the antioxidant capacity of the white sesame, and also if the two methods of assessing antioxidant capacity in vitro are directly correlated. Therfore, it was observed a significant correlation $(\mathrm{p} \leq 0.05)$ and positive between the three methods: ABTS, FRAP and total phenolics (Table 1).

Considering the two methods evaluated (ABTS and FRAP) it was verified an increase of antioxidant capacity with a higher germination time at $30{ }^{\circ} \mathrm{C}(\mathrm{p} \leq 0.05)$ (Figures $\left.3 \mathrm{a}, \mathrm{b}\right)$. Authors as López-Amorós et al. (2006) found a higher antioxidant capacity in mung beans in a period between 4 and 6 days. Also, Lin \& Lai (2006) observed a higher in antioxidant capacity in soy and mung beans after the germination, and could be explained by the bioquimic metabolism of the grains during the germination, producing anthocyanins and flavonoids which help increasing the antioxidant capacity (Randhir et al., 2004). Furthermore, Hahm et al. (2009), found a significant increase of sesamol (phenolic antioxidant) from the second to the third day of sesame germination. This increase is due to great germination temperature for the sesame seeds $\left(35^{\circ} \mathrm{C}\right)$, while temperatures below $20^{\circ} \mathrm{C}$ does not have a good condition for germination. Moreover, Abderrahim et al. (2012) reported an increase of antioxidant activity in amaranth seeds in the first 96 hours of germination and in canihua seeds until 72 hours of germination. López-Amorós et al. (2006) found a higher value of antioxidant capacity in beans after 6 days of germination and without luminosity, which means that some foods do not need light presence, as occurred in this study, where the germination process occurred inside a greenhouse without photoperiod.

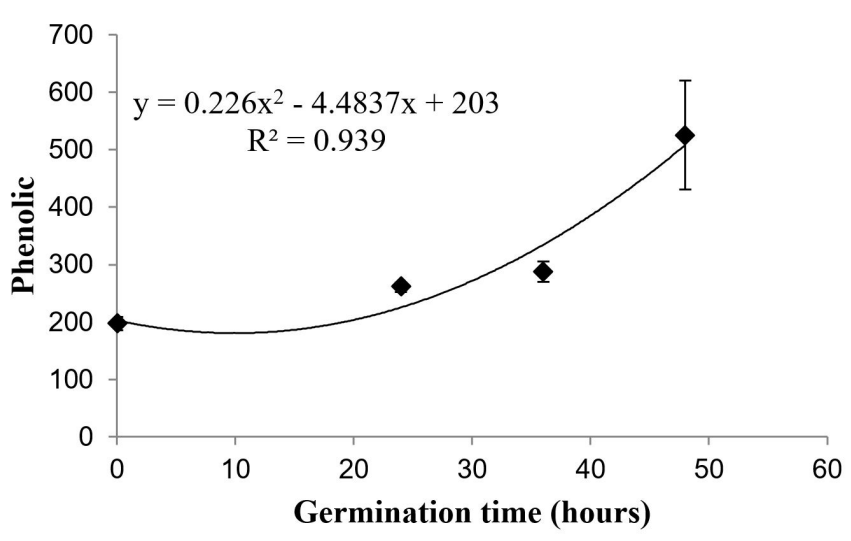

Figure 2. Interference of white sesame germination time about the total phenolic compound levels.

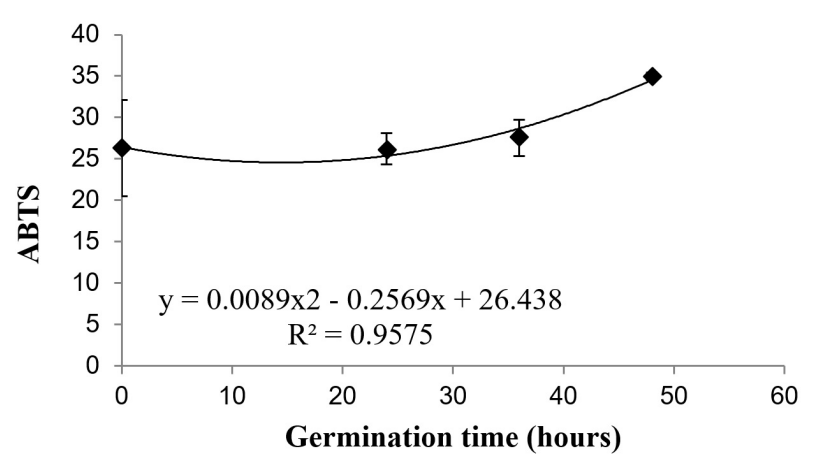

(a)

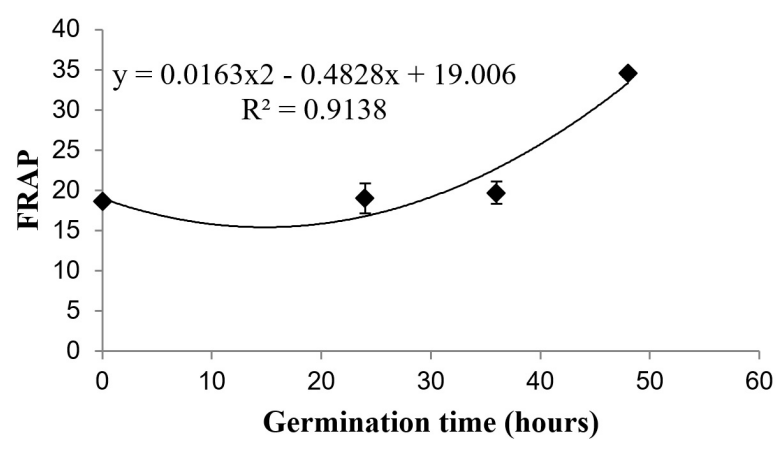

(b)

Figure 3. Interference on white sesame germination time about antioxidant capacity by ABTS (a) and FRAP (b) methods.

Table 1. Pearson coefficients between different methods evaluated for the antioxidant capacity of white sesame.

\begin{tabular}{cc}
\hline Correlations & Pearson coefficients $(\mathbf{r})$ \\
\hline ABTS $\times$ FRAP & $0.761^{\star}$ \\
FRAP $\times$ Phenolic & $0.920^{\star}$ \\
Phenolic $\times$ ABTS & $0.711^{\star}$
\end{tabular}

${ }^{*}$ Significant values $(\mathrm{p} \leq 0.05)$.

\section{Conclusion}

The increase in germination time of white sesame seeds in a greenhouse at $30^{\circ} \mathrm{C}$ decreases the levels of lipids, proteins and ashes and increases substantially the moisture levels. Also, 
there is an increase in phenolic compounds levels, as well as in antioxidant capacity when determined by FRAP and ABTS methods.

Based on the present study and in other similar, it's possible to affirm that the germination process increases the antioxidant capacity of white sesame seeds, however more studies are needed to evaluate a better environmental condition of germination and other factors that could modify its composition.

\section{Referências}

Abderrahim, F., Huanatico, E., Repo-Carrasco-Valencia, R., Arribas, S. M., Gonzalez, M. C., \& Condezo-Hoyos, L. (2012). Effect of germination on total phenolic compounds, total antioxidant capacity, Maillard reaction products and oxidative stress markers in canihua (Chenopodium pallidicaule). Journal of Cereal Science, 56(2), 410417. http://dx.doi.org/10.1016/j.jcs.2012.04.013.

Amistá, M., \& Tavano, O. (2013). The effect of germination and heat treatment on the protein digestibility and trypsin inhibition activity of quinoa grains. Brazilian Journal of Food Technology, 16(1), 52-58.

Arriel, N., Firmino, P., Beltrão, N., Soares, J., Araújo, A., Silva, A., \& Ferreira, G. (2007). Plantar collection: the sesame culture. Brasília: Embrapa Technology Information. $72 \mathrm{p}$.

Association of Official Analytical Chemists - AOAC. (2012). Official methods of analysis (19th ed.). Gaithersburg: AOAC International.

Chen, P., Chien, K., Su, T., Chang, C., Liu, T., Cheng, H., \& Tsai, C. (2005). Dietary sesame reduces serum cholesterol and enhances antioxidant capacity in hypercholesterolemia. Nutrition Research (New York, N.Y.), 25(6), 559-567. http://dx.doi.org/10.1016/j. nutres.2005.05.007.

Food and Agriculture Organization - FAO. (2014). FAO statistical yearbook. Food and Agriculture Organization of the United Nations Regional Office for Asia and the Pacific Bangkok.

Hahm, T. S., Park, S. J., \& Martin Lo, Y. (2009). Effects of germination on chemical composition and functional properties of sesame (Sesamum indicum L.) seeds. Bioresource Technology, 100(4), 1643-1647. PMid:18976903. http://dx.doi.org/10.1016/j.biortech.2008.09.034.

Hassani, A., Procopio, S., \& Becker, T. (2016). Influence of malting and lactic acid fermentation on functional bioactive components in cereal-based raw materials: a review paper. International Journal of Food Science \& Technology, 51(1), 14-22. http://dx.doi.org/10.1111/ ijfs. 12965.

Kaukovirta-Norja, A., Wilhelmsson, A., \& Poutanem, K. (2004). Germination: a means to improve the functionality of oat. Agricultural and Food Science, 13(1/2), 100-112.

Larrauri, A., Rupérez, P., \& Saura-Calixto, F. (1997). Effect of drying temperature on the stability of polyphenols and antioxidant activity of red grape pomace peels. Journal of Agricultural and Food Chemistry, 45(4), 1390-1393. http://dx.doi.org/10.1021/jf960282f.

Lin, P. Y., \& Lai, H. M. (2006). Bioactive compounds in legumes and their germinated products. Journal of Agricultural and Food Chemistry, 54(11), 3807-3814. PMid:16719500. http://dx.doi. org/10.1021/jf060002o.

López-Amorós, M., Hernández, T., \& Estrella, I. (2006). Effect of germination on legume phenolic compounds and their antioxidant activity. Journal of Food Composition and Analysis, 19(4), 277-283. http://dx.doi.org/10.1016/j.jfca.2004.06.012.
Martinez, A. P. C., Martinez, P. C. C., Souza, M. C., \& Brazaca, S. G. C. (2011). Alterações químicas em grãos de soja com a germinação. Ciência e Tecnologia de Alimentos, 31(1), 23-30. http://dx.doi. org/10.1590/S0101-20612011000100004.

Mbithi, S., Van Camp, J., Rodriguez, R., \& Huyghebaert, A. (2001). Effects of sprouting on nutrient and antinutrient composition of kidney beans (Phaseolus vulgaris var. Rose coco). European Food Research and Technology, 212(2), 188-191. http://dx.doi.org/10.1007/ s002170000200.

Megat, R., Noraliza, W., Azrina, A., \& Zulkhairi, A. (2011). Nutritional changes in germinated legumes and rice varieties. International Food Research Journal, 18, 705-713.

Miller, N. J., Rice-Evans, C., Davies, M. J., Gopinathan, V., \& Milner, A. (1993). A novel method for measuring antioxidant capacity and its application to monitoring the antioxidant status in premature neonates. Clinical Science, 84(4), 407-412. PMid:8482045. http:// dx.doi.org/10.1042/cs0840407.

Ohtsubo, K., Suzuki, K., Yasui, Y., \& Kasumi, T. (2005). Bio-functional components in the processed pregerminated brown rice by a twinscrew extruder. Journal of Food Composition and Analysis, 18(4), 303-316. http://dx.doi.org/10.1016/j.jfca.2004.10.003.

Pathak, N., Rai, A. K., Kumari, R., \& Bhat, K. V. (2014). Value addition in sesame: a perspective on bioactive components for enhancing utility and profitability. Pharmacognosy Reviews, 8(16), 147-155. PMid:25125886. http://dx.doi.org/10.4103/0973-7847.134249.

Pulido, R., Bravo, L., \& Saura-Calixto, F. (2000). Antioxidant activity of dietary polyphenols as determined by a modified ferric reducing/ antioxidant power assay. Journal of Agricultural and Food Chemistry, 48(8), 3396-3402. PMid:10956123. http://dx.doi.org/10.1021/jf9913458.

Queiroga, V., Gondim, T., Vale, D., Gereon, H., Moura, J., Silva, P., \& Souza, J. Fo. (2008). Organic sesame production in the communities of family producers of São Francisco de Assis do Piaui. Campina Grande: Embrapa/Cnpa. 127 p.

Randhir, R., Lin, Y.-T., \& Shetty, K. (2004). Stimulation of phenolic, antioxidant and antimicrobial activities in dark germinated mung bean sprouts in response to peptide and phytochemical elicitors. Process Biochemistry, 39(5), 637-646. http://dx.doi.org/10.1016/ S0032-9592(03)00197-3.

Rufino, M., Alves, R., Brito, E., Morais, S., Sampaio, C., Pérez-Jimenez, J., \& Saura Calixto, F. (2007). Scientific methodology: total antioxidant capacity determination in fruits by the capture of free radical ABTS. Fortaleza: Emprapa. 4 p.

Rufino, M., Alves, R., Brito, E., Morais, S., Sampaio, C., Pérez-Jimenez, J., \& Saura Calixto, F. (2006). Scientific methodology: total antioxidant capacity determination in Fruits by Iron Reduction Method (FRAP). Fortaleza: Embrapa. $4 \mathrm{p}$

Ruiz, A., \& Bressani, R. (1990). Effect of germination on the chemical composition and nutritive value of amaranth grain. Cereal Chemistry, 67(6), 519-522.

Silva, E., Oliveira, H., Araújo, L., Guilherme, M., \& Maracujá, P. (2014). Morphological characterization and physiological quality of sesame seeds. Green Journal of Agroecology and Sustainable Development, 9(3), 149-156.

Troszynska, A., Wolejszo, A., Narolewska, O. (2006). Effect of germination time on the content of phenolic compounds and sensory quality of mung bean (Vigma radiate L.) sprouts. Polish Journal of Food and Nutrition Sciences, 15/56(4), 453-459. 
Vizzoto, M., Krolow, A., \& Teixeira, F. (2010). Functional foods: basic concepts. Pelotas: Embrapa Clima Temperado. 20 p.

Waterhouse, A. L. (2002). Determination of total phenolics. Current Protocols in Food Analytical Chemistry, (Suppl. 6), 1-8. http://dx.doi. org/10.1002/0471142913.faa0101s06.

Xu, J. G., Tian, R., Hu, P., Luo, Y., Wang, D., \& Tian, D. (2009). Dynamic changes in phenolic compounds and antioxidant activity in oats (Avena nuda L.) during steeping and germination. Journal of Agricultural and Food Chemistry, 57(21), 10392-10398. PMid:19827789. http:// dx.doi.org/10.1021/jf902778j.

Žilić, S., Basić, Z., Hadži-Tašković Šukalović, V., Maksimović, V., Janković, M., \& Filipović, M. (2014). Can the sprouting process applied to wheat improve the contents of vitamins and phenolic compounds and antioxidant capacity of the flour? International Journal of Food Science \& Technology, 49(4), 1040-1047. http:// dx.doi.org/10.1111/ijfs.12397. 